\title{
PERITONEAL TUBERCULOSIS IN A PATIENT WITH ANKYLOSING SPONDYLITIS USING IMMUNOBIOLOGICALS - A RARE CASE
}

Marília Simões Bianchini ${ }^{1, *}$, Éviny Knupp da Silva ${ }^{1}$, Filipe Marçal Pires ${ }^{1}$, Geovane Henrique Gonçalves ${ }^{1}$, Júlia Fontes Parizzi ${ }^{1}$,

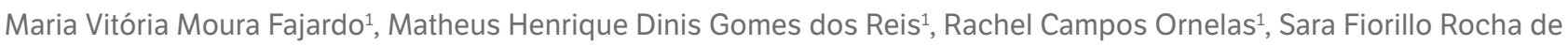
Resende $^{1}$, Talita Ramos Siqueira ${ }^{1}$, Thaís Campino Siqueira ${ }^{1}$, Vinícius Rodrigues Faria ${ }^{1}$, Yan Oliveira Pereira ${ }^{1}$

1. Universidade Federal de Juiz de Fora, Governador Valadares (MG), Brazil.

*Corresponding author: marilia_bianchini27@yahoo.com.br

\section{BACKGROUND}

Ankylosing spondylitis is an inflammatory disease that belongs to the spondyloarthritis group. It is characterized by axial skeletal involvement and its etiology is not well elucidated. The main symptom is the presence of inflammatory low back pain and prolonged morning stiffness in the axial skeleton. Treatment includes NSAID and immunobiological drugs in order to improve lumbar stiffness and prevent the progress of the disease.

\section{CASE REPORT}

Male patient, 40 years old, complaining of inflammatory low back pain and morning stiffness, that started 6 months ago, is associated with pain in the Achilles tendon region. He has presented lumbar movement limitations in the sagittal and frontal plane on the musculoskeletal examination; decreased chest expansion; and Schober's test of $12 \mathrm{~cm}$. Laboratory tests revealed C-reactive protein (CRP) $15 \mathrm{mg} / \mathrm{L}$; erythrocyte sedimentation rate (ESR) $23 \mathrm{~mm} / \mathrm{h}$; negative rheumatoid factor (latex) and positive HLAB 27 by CRP. It was possible to identify the presence of bilateral sacrum ileitis at the magnetic resonance imaging (MRI); and at the spine MRI was acknowledged syndesmophytes. According to the ASA's criteria, it has already been classified as ankylosing spondylitis, and the use of NSAID was recommended. However, it had little improvement in symptoms, this way immunobiological drugs were proposed. Before the start of the treatment with immunobiological drugs, a PPD test of $13 \mathrm{~mm}$ was verified in the patient. Thus, a chemoprophylaxis with isoniazid was instituted for 9 months. After the first month, adalimumab was started. Symptoms improved after the first month. But in the second month, fever, important weight loss and a severe constricting abdominal pain in the epigastrium, which irradiated to the right hypochondrium, had started. The use of the immunobiological drugs was suspended and the patient was hospitalized. At the physical examination, significant ascites (positive fluid thrill) and bilateral inguinal lymph node enlargement were observed. Despite the negative test for Mycobacterium tuberculosis, the strong clinical suspicion, elevation of adenosine deaminase, and previous use of immunobiological drugs led to the diagnosis of peritoneal tuberculosis. In this way, an empirical treatment with RIPE started. The result was absence of the ascites in the first month of treatment, regression of the fever and improvement in laboratory parameters.

\section{CONCLUSION}

Peritoneal tuberculosis is an unusual location of extrapulmonary infection, but it must always be suspected in face of an abdominal pain, fever and ascites in patients with autoimmune disease using immunobiological rugs. The treatment has to be established, even if empirical. 